\title{
Article
}

\section{Exploring the relationship between sleep quality, emotional well-being and aggression levels in a European sample}

Freitag, Lara, Ireland, Jane Louise and Niesten, Isabella J.M.

Available at http://clok.uclan.ac.uk/16000/

Freitag, Lara, Ireland, Jane Louise ORCID: 0000-0002-5117-5930 and Niesten, Isabella J.M. (2017) Exploring the relationship between sleep quality, emotional well-being and aggression levels in a European sample. Journal of Aggression, Conflict and Peace Research, 9 (3). ISSN 1759-6599

It is advisable to refer to the publisher's version if you intend to cite from the work. http://dx.doi.org/10.1108/AACPR-08-2016-0239

For more information about UCLan's research in this area go to http://www.uclan.ac.uk/researchgroups/ and search for <name of research Group>.

For information about Research generally at UCLan please go to http://www.uclan.ac.uk/research/

All outputs in CLoK are protected by Intellectual Property Rights law, including Copyright law. Copyright, IPR and Moral Rights for the works on this site are retained by the individual authors and/or other copyright owners. Terms and conditions for use of this material are defined in the policies page.

\section{CLoK}

Central Lancashire online Knowledge www.clok.uclan.ac.uk

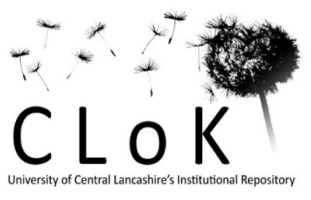


Exploring the relationship between sleep quality, emotional well-being and aggression levels in a European sample

\author{
Lara Freitag \\ Faculty of Psychology and Neuroscience, Maastricht University \\ The Netherlands
}

Jane L. Ireland ${ }^{1}$

School of Psychology, University of Central Lancashire, Preston, United Kingdom

Isabella J. M. Niesten,

Faculty of Psychology and Neuroscience, Maastricht University, The Netherlands

\footnotetext{
${ }^{1}$ Corresponding author. JLIreland1@uclan.ac.uk
} 


\begin{abstract}
Sleep deprivation is well known to negatively affect mood, cognition and behaviour. The current study explored the relationship between sleep quantity, subjective sleep quality and aggression, hostility and well-being levels among adults in a non-clinical population. Two hundred and one participants aged 18 and above from Germany, UK and the Netherlands completed an online survey consisting of a sleep quality index (PSQI) along with measures of psychological well-being, implicit and explicit aggression, and intent attributions. Sleep disturbances were expected to increase hostile attributions and emotional problems such as irritability, distress and inner tension. Additionally, poor sleep quality was expected to predict increased (reactive) aggression. Our results confirmed that sleep disturbances were related to decreased levels of psychological well-being. Subjective poor sleep quality predicted increased hostile attributions. The overall sleep experience however was not associated with aggression levels. Nevertheless, both a poor sleep experience and low sleep quality were related to increased reactive aggression, but only in British participants. Current findings highlight the importance of sleep quality rather than sleep quantity in predicting hostile and aggressive behaviours, particularly perceived quality.
\end{abstract}

Keywords: Sleep and aggression, PSQI, sleep quality, psychological well-being 
Exploring the relationship between sleep quality, emotional well-being and aggression levels in a European sample

Sleep has an important role in both physical and psychological well-being, with sleep deprivation impacting on cognitive abilities, emotional states such as anger, sadness and fear, and general psychological well-being (e.g. Steptoe, O’Donnell, Marmot \& Wardle, 2008; Franzen et al, 2009; Walker, 2009). In addition, poor sleep quality is associated with reduced attention and memory, increased irritability, impatience, inner tension, depression and anxiety (Buboltz, Brown \& Soper, 2001), with those presenting with increased trait hostility shown to have particular difficulties with sleep quality (Taylor, Fireman \& Levin, 2013). O'Brien and colleagues (2001) further showed that sleepiness in students, resulting from poor sleep quality, could even predict conduct problems and aggression in school; students who regularly engaged in bullying or other aggressive behaviours were found more likely to exhibit daytime sleepiness than their non-aggressive classmates.

Theoretical underpinnings of aggression, such as the General Aggression Model (GAM; Anderson \& Bushman, 2002), suggest cognition as a key element in the promotion of an aggressive response. According to the GAM, aggression largely depends on how an individual perceives and interprets the environment, on their expectations, and their knowledge and beliefs concerning how others will typically respond in certain situations. One potentially key element linking cognition and aggression are Hostile Attribution Biases. This describe the tendency to interpret others' ambiguous behaviour as having hostile intent (Nasby, Hayden \& DePaulo, 1980) and reacting accordingly. It can have a trait basis (Taylor et al, 2013). This apparent hostile bias in social information processing can arguably be aggravated by poor sleep as a result of cognition becoming affected.

Regarding aggression, researchers have increasingly supported the notion of two specific forms: reactive and proactive (Ellis, Weiss \& Lochman, 2009). Reactive is an emotion-based impulsive aggression usually performed in response to fear or anger when a goal is blocked or there is provocation. Proactive, however, is more planned aggression that is not impulsive (Morgan, 2004). Capturing both forms is considered important. For example, in a study exploring neurocognitive and social cognition processes, it was found that problems with response inhibition were associated with reactive but not proactive aggression (Ellis et al., 
2009). As sleepiness has been found to impair emotional regulation mechanisms in the prefrontal cortex (Kamphuis, Meerlo, Koolhaas \& Lancel, 2012; O’Brien et al., 2001), it may in turn lead to a loss of control over emotions. This includes an inability to regulate aggressive impulses in response to provocative behaviours. Thus an association between aggression and sleep becomes expected.

Further studies have shown increased impulsivity, disruptive behaviour and aggression after experimental sleep loss. In studies involving rats, Licklider and Bunch (1946) compared the behaviour of four groups of rats that were kept awake for 12, 16, 20, and 24 hours respectively. All rats that had been forced to stay awake for 24 hours died after 3 to 14 days, not from sleep loss per se, but largely from engaging in aggression. The sleep deprivation caused them to become hypersensitive so that even slight physical contact produced vicious, aggressive behaviours (Licklider \& Bunch, 1946). This was replicated in a later study by De Paula \& Hoshino (2000).

An association with sleep deprivation and the factors associated with aggression have also been found in humans; sleep deprivation has been found to increase anger, impulsivity and short-tempered responses (Kahn-Greene et al, 2006; Kamphuis et al, 2012). In the KahnGreene et al study (2006) participants were asked to write a response for a cartoon character that was confronted with a frustrating situation, once at rested baseline and again following 55 hours of continuous wakefulness. Compared to baseline, sleep deprivation was associated with an increased tendency to avoid responsibility by assigning blame to others and an increased outward expression of aggressive responses. Thus, results showed that two nights of sleep loss were related to a decreased capacity to tolerate frustration and a decrease in the suppression of impulses; aggressive and hostile impulses in particular. Consequently, the authors suggest that sleep deprivation weakens the inhibition of aggression.

As association between sleep and aggression or hostility has also been found across populations. Ireland and Culpin (2006) explored sleep problems, trait aggression and trait hostility in a population of juvenile and young offenders. They found increased aggression related to the quantity and quality of reported sleep, with reduced quantity and quality predicted by increased overall aggression. A particular role for hostility was highlighted; increased hostility was found to be predictive of reduced hours of sleep and poor sleep quality. In another study with a non-general sample, Haynes and colleagues (2006) found 
that inadequate amounts of sleep were associated with aggression in adolescents recently treated for substance abuse. These findings remained even when confounds such as baseline aggression and frequency of substance abuse were controlled for. They also found that improvements in sleep time were associated with significant decreases in the reporting of aggressive thoughts and actions. Other studies found similar results, namely behavioural improvements and a reduction of disruptive behaviours after successful treatment of sleep disturbances (Ali, Pitson \& Stradling, 1996; Mitchell \& Kelly, 2006).

Given evidence for the negative consequences of sleep deprivation, there seems to be a need for research to focus on this area. The relationship between sleep problems and physical or psychological impairments, such as daytime fatigue, lack of concentration and poor psychological well-being are certainly well documented (Buboltz et al., 2001). Sleep loss has been related to greater feelings of depression, confusion, anger and subjective feelings of frustration (James \& Gregg, 2004). It has also been associated with a wide range of psychiatric disorders including mood and anxiety disorders, schizophrenia and substancerelated disorders (Benca, 1996). Research looking specifically at the relationship between sleep and aggression suggests that inadequate sleep is associated with an increase in aggressive and hostile thoughts and actions. However, the literature on the link between sleep and aggression or hostility, as noted, is still relatively scarce.

Sleep deprivation alone does not appear to be the only variable of interest. Sleep quality is also known to be important. In an effort to compare the effects of both sleep quantity and sleep quality on several measures of health, Pilcher, Ginter and Sadowsky (1996) asked participants to complete a seven day sleep log followed by surveys pertaining to physical health, psychological well-being and sleepiness. Results showed that sleep quality was significantly better associated with measures of health, well-being, and sleepiness than sleep quantity. Indeed, sleep quality better predicted overall health, affect balance, satisfaction with life and feelings of tension, anger, depression and fatigue.

Even though sleep quality and quantity can overlap, there is a qualitative difference between these two factors; whereas sleep quantity includes objective quantifiable components such as sleep duration and sleep latency, sleep quality largely comprises subjective assessments. It reflects an individual's general satisfaction with the sleep experience by integrating sleep 
initiation, duration, number of awakenings at night, and feelings of restfulness or tiredness upon awakening (Harvey et al, 2008).

A closely related area that may be important to capture but has been somewhat neglected is the cognitive component of sleep, namely the perception of how much sleep a person has had and how good they perceived this sleep to be. Interestingly, individuals who are informed their sleep quality is above average showed improved cognitive abilities, whereas individuals falsely told they had slept badly, performed significantly worse. For example, Draganich and Erdal (2014) had 164 participants report on their previous night's sleep quality. They were then randomly assigned to either a control, above average or below average sleep quality condition. After engaging in cognitive tasks, results showed that falsely telling individuals they slept badly exerted negative effects on their cognitive abilities. Likewise, participants in the above average sleep condition performed better on the cognitive tests regardless of their own subjective perception of how well they slept. The assigned sleep condition, rather than the individuals' subjective perception, predicted their scores on the cognitive tasks. These findings provide some evidence for a sleep placebo effect and support the hypothesis that beliefs can have a strong influence on the effects of sleep.

A recent study has tried to examine the role of cognition with sleep quantity and quality, exploring how this associated with aggression motivation (i.e. reactive and proactive) and hostile cognitions in a male prisoner sample (Barker, Ireland, Chu \& Ireland, 2016). Incorporating two studies, they demonstrate that objective indicators of sleep quantity and quality did not associate with aggression whereas the subjective perception of poor sleep did; prisoners perceiving poor sleep were more likely to report increased proactive and reactive aggression levels than those perceiving good sleep. This is also consistent with Tsuchiyama et al (2013) who, using a non-clinical sample, demonstrated that poor self-reported sleep quality predicted higher levels of hostility whereas objective measures of sleep did not. It is the subjective perception of sleep therefore that is appearing to be important, with this negatively impacting on social information processing (Draganich \& Erdal, 2014) and subsequent hostility and aggression.

The current study aims to build on these earlier studies by exploring the relationship between self-reported sleep quality and sleep quantity with levels of aggression, hostility and wellbeing in a European sample. The following hypotheses were made: 1.) Sleep problems will 
predict increased aggression levels; 2.) Perceived poor sleep quality will predict levels of aggression rather than sleep quantity; 3.) Sleep problems will predict increased reactive aggression as opposed to proactive aggression; 4.) Sleep problems will be associated with increased emotional problems such as irritability, nervousness, impulsivity and inner tension; 5.) Sleep problems will predict increased hostile attributions.

\section{Method}

\section{Participants}

Two hundred and seventy-eight participants took part in this study. Six did not consent to the scope of the study and were consequently excluded $(\mathrm{N}=272)$. Another 71 participants had to be excluded due to missing data. The final completion rate was $72 \%$. The final sample $(\mathrm{N}=$ 201) ranged in age from 18 to 65 years of age ( $M=29.3$ years, $S D=11.0$ years). It consisted of 149 women and 51 men, with one participant not indicating their sex. Participants were recruited from three different countries with 60 participants being British, 103 German, 37 Dutch and one not indicating their nationality. The sample was split between students $(\mathrm{N}=$ 104) and non-students ( $\mathrm{N}=95)$. Two participants could not be classified as either student or non-student. Table 1 includes an overview of participants' demographic data.

$<$ Insert Table 1>

\section{Measures}

All participants completed the following self-report measures:

Pittsburgh Sleep Quality Index (PSQI; Buysse \& Reynolds, 1989): The PSQI is a self-rated questionnaire assessing the quantity and quality of sleep in adults. It focused on the past month. It differentiates poor from good sleep quality by measuring 19 individual items weighted on a 0-3 interval scale with higher scores indicating greater sleep disturbance. Items cover seven different areas: subjective sleep quality, sleep latency, sleep duration, habitual sleep efficiency, sleep disturbances, use of sleeping medications, and daytime dysfunction over the past month. The global PSQI score is calculated by adding the seven component scores. Higher scores indicate higher levels of sleep disturbances. 
Psychological General Well-Being Index (PGWBI; Dupuy, 1984): The PGWBI captures depressed mood, anxiety, positive well-being, self-control, general health and vitality over the past month. The shortened version was used, comprising eight items (Grossi et al., 2006). Items are scored on a 0-5 scale with higher scores indicating greater perceived well-being.

Buss-Perry Aggression Questionnaire (AQ; Buss, \& Perry, 1992): Focusing on trait aggression, participants rank 29 statements along a 7-point continuum ranging from 'extremely uncharacteristic of me' to 'extremely characteristic of me'. It captures physical aggression, verbal aggression, anger and hostility. Higher scores indicate a greater level of aggression.

Impulsive Premeditated Aggression Scale (IPAS, Stanford et al., 2003): The IPAS focuses on impulsive or predominantly premeditated aggression. It comprises eight screening questions asking whether and how often the individual engaged in a range of aggressive acts, either verbally or physically aggressive, over the past month. Participants are then asked to consider those acts and indicate their agreement with 30 items scored on a 5-point continuum ranging from 'strongly agree' to 'strongly disagree'. Eighteen of these items capture the extent to which their act was impulsive or premeditated, with 12 items serving as unscored filler items.

Making Judgements Questionnaire (MJQ from the Affective Cognitive and Lifestyle measure; Ireland et al, in press): The MJQ is a conditional reasoning test used to assess hostile attribution biases. It describes ten situations in which the intent of the agitator is unclear or ambiguous. Participants are asked to answer one question for each story, assessing their assumptions of the agitator's intent.

\section{Procedure}

Ethical approval was obtained from the Ethics Committee of the University of Central Lancashire. Participants were approached online using chain sampling, a nonprobability sampling technique where existing study subjects recruit future subjects from 
among their acquaintances. Adverts inviting participation were published on several social networking sites, namely LinkedIn, Xing, Facebook, Call for Participants and the British Psychological Society (BPS). The survey link was also included in newsletters of Maastricht University and University of Central Lancashire calling for participants. Those aged 18 and above from Germany, United Kingdom and the Netherlands were invited to take part. The online questionnaire included an information sheet with details about the scope of the study. Participants provided informed consent, agreeing with the study requirements by ticking a box at the beginning of the questionnaire after being briefed.

\section{Results}

\section{Data screening and analysis}

Correlational analyses were conducted using Pearson correlation and linear regression analysis. To control for the effect of relevant demographic variables (i.e. sex, age, profession) and sleeping medication, these were entered as variables in the regression analyses ${ }^{2}$. Prior to analysis, the data was screened for outliers and missing data. No outliers were detected. Regarding the replacement of missing values, if less than $25 \%$ of the data on a measure was missing this was replaced with the variable mean, once it was determined that the data was randomly missing. This was addressed per participant.

\section{Sleep, well-being and aggression measures}

Reliabilities of all measures were assessed by calculating Cronbach's $\alpha$. All measures showed high degrees of internal consistency (See Table 2). Means and standard deviations on all measures across nationalities, sex, and sample are shown in Table 3.

$<$ Insert Table 2>

$<$ Insert Table 3>

\footnotetext{
${ }^{2}$ This controls for differences in these variables across measures/variables of interest. Differences were noted on sleep and well-being across nationality, sex and sample, which meant they had to be controlled for in addition to sleeping medication.
} 
Average hours sleep reported was 7.15 hours. Over half of participants rated their sleep quality as fairly good (55\%). One fifth (21\%) indicated very good sleep quality whereas another fifth $(21 \%)$ perceived their sleep to be fairly bad. Only $3 \%$ of individuals rated their sleep quality as very bad.

\section{Sleep disturbances and aggression levels}

<Insert Table 4>

Multiple linear regressions using the 'Enter' method were performed with impulsive and premeditated aggression types as IVs and PSQI global score, sleep quantity, and sleep quality as DVs. Results showed that aggression types did not significantly predict overall PSQI score $(F(3,197)=1.24 n s)$, sleep quantity $(F(3,197)=1.84 n s)$, or sleep quality $(F(3,197)=.67 n s)$. Follow-up analyses tested whether increased sleep disturbances were associated with increased impulsive aggression. A linear regression was performed with impulsive aggression as IV and PSQI score as DV. Impulsive aggression did not significantly predict sleep index scores $(F(1,199)=.15 n s)$.

Aggression types did not significantly predict overall PSQI score for British participants $(F(2,57)=2.9 n s)$ but impulsive aggression was found to be a significant predictor of the PSQI score $(p=.03)$, with increased levels of impulsive aggression predicting increased sleep disturbances. Impulsive aggression also significantly predicted sleep quality $(p=.03)$ with increased impulsive aggression predicting decreased sleep quality. There were no significant findings with premeditated aggression or aggression motivation. For German and Dutch participants the regression analyses were non-significant across all sleep variables.

When the regression analyses were performed on the student and the general sample separately, results showed that aggression types did not significantly predict overall PSQI score $(F(2,101)=.77 n s)$, sleep quantity $(F(2,101)=2.03 n s)$ or sleep quality $(F(2,101)=$ $.13 n s)$ for the student sample. For the general sample, aggression types significantly predicted PSQI global score $\left(F(2,90)=3.68, p=.03, R^{2}=.076\right)$, with impulsive aggression being significant $(p=.02)$ and associated with increased sleep disturbances. There were no significant findings with premeditated aggression or aggression motivation. 


\section{Sleep disturbances and levels of psychological well-being}

The correlation coefficient between the overall sleep index (PSQI) score and general wellbeing (PGWBI) scores indicated a strong negative relationship between the two variables $(r=$ -.64) in the overall sample. That is, the greater the sleep disturbances are (indicated by higher PSQI scores), the lower the levels of well-being are. The association was stronger among British $(r=-.68)$ and Dutch $(r=-.65)$ participants but weaker among German participants $(r$ $=-.54)$.

Sleep was then included as a continuous variable and a linear regression analysis performed using the 'Enter' method with well-being scores as the IV and sleep index scores as the DV. Well-being scores significantly predicted overall PSQI score $\left(F(1,199)=134.45, p<.001, R^{2}\right.$ $=.403$ ), with higher levels of well-being predicting decreased sleep disturbances. The same linear regression analyses were performed across nationalities. Again, well-being scores were found to significantly predict sleep index scores for British $\left(F(1,58)=50.1, p<.001, R^{2}\right.$ $=.463)$, German $\left(F(1,101)=42.45, p<.001, R^{2}=.296\right)$ and Dutch participants $(F(1,35)=$ 25.93, $p<.001, R^{2}=.426$ ), with higher well-being scores predicting better sleep.

\section{Sleep disturbances and hostile attributions}

A correlation coefficient between sleep quality and hostile attributions indicated a weak yet significant positive association between the two variables $(r=.15, p=.04)$. Higher sleep quality scores indicated worse subjective sleep quality and this in turn seemed to be related to higher cognitive hostility levels. To test whether sleep disturbances would be associated with increased hostile attributions, multiple linear regressions using the 'Enter' method were performed with hostile attributions as the IV and sleep index scores, sleep quantity, and sleep quality as the DVs.

Hostile attributions did not significantly predict overall PSQI score $(F(1,199)=2.68 n s)$. Likewise, hostility did not significantly predict sleep quantity $(F(1,199)=.19, p=.67 n s)$. However, when sleep quality was used as the DV, results showed that hostile attributions significantly predicted sleep quality scores $\left(F(1,199)=4.35, p=.04, R^{2}=.021\right)$, with higher levels of hostility predicting decreased sleep quality. Participants with the highest sleep quality were the least likely to assume a hostile intent in an ambiguous situation. 


\section{Discussion}

The current study highlighted the importance of sleep as a variable associated with aggression, hostility and psychological well-being. Sleep disturbances were associated with increased impulsive aggression in British participants. Poor quality of sleep was also related to increased impulsive aggression. Additionally, poor sleep quality was associated with decreased levels of well-being and hostile attribution styles in the overall sample. The quantity of sleep did not associate with either aggression or hostility.

\section{Increased aggression and sleep quality and quantity}

Findings did not generally support the expectation that sleep disturbances would be associated with increased aggression levels, with subjective sleep quality being the crucial factor in this prediction. Similarly, results did not confirm our prediction that reactive aggression levels were expected to increase with higher sleep problems. However, findings were different across countries in some respect; a negative overall sleep experience was associated with increased impulsive aggression levels among British participants. Poor sleep quality was also related to increased impulsive aggression in this group. Sleep quantity was found to be unrelated to aggression levels. This finding is consistent with previous research showing that sleep quality may be more important than sleep quantity in the relationship between sleep problems, negative emotions and behaviours, such as anger and aggression (Kamphuis et al., 2012). The findings of an association between sleep and aggression are also consistent with previous research demonstrating inadequate sleep relates to an increased outward expression of aggressive responses (Kahn-Greene et al., 2006). However, inconsistent with previous research (Barker et al., 2016), the current study found poor sleep to be related to increased reactive aggression only. There was no association found between sleep and proactive (premeditated) aggression. Given that previous research has found inadequate sleep to impair emotional regulation processes (O'Brien et al., 2001), it could be speculated that this might lead to a loss of control over emotions that in turn increases reactive aggressive responding. In contrast, proactive aggression is a more goal-directed behaviour and usually requires some form of planning that may therefore be inoculated against the negative impacts of inadequate sleep. 
The current study supports a role for sleep quality in the relationship with aggression. Considering the General Aggression Model (Anderson \& Bushman, 2002), it could be argued that sleep quality might impact negatively on cognitive functioning (Koffel \& Watson, 2009), promoting emotional difficulties that in turn might raise implicit aggression tendencies and promote the activation of hostile attribution biases. This is in line with previous research showing that poor self-reported sleep quality is associated with poor cognitive performance in healthy individuals (Nebes et al, 2009).

Poor sleep quality was unrelated to increased aggression levels among German and Dutch participants. This was inconsistent with the prediction that sleep quality would be associated with aggression levels across the whole sample, with the predicted association only found among British participants. However, British participants reported more difficulties with sleep (see Table 3) than German and Dutch participants. The quality of sleep in the UK is thought to be among the lowest across countries (Sleep Cycle, 2014). Given that German and Dutch participants in the current study reported to have lower levels of sleep disturbances and a higher sleep quality than British participants, it could be speculated that this might be why there was no effect of sleep quality on aggression levels found among the two former groups.

\section{Increased hostility and sleep quality and quantity}

The results did not support our prediction that a negative overall sleep experience would be associated with increased hostile attribution styles. Sleep quantity was also not associated with hostile attributions. However, the results indicated how, again, subjective sleep quality rather than sleep quantity is the crucial factor in predicting hostile attributions. This finding is in line with previous research that has found a negative relationship between cognitive components of hostility, such as hostile attribution styles and sleep quality (Taylor et al, 2013). However, due to the correlational nature of most studies, including the current one, it is still unclear whether increased hostility is caused by poor sleep quality, leads to poor sleep quality, or it is a combination of the two. It could be that the relationship between subjective sleep quality and cognitive hostility is reciprocal; individuals high in hostility might be at risk for decreased sleep quality, with poor sleep then exacerbating hostile interpretations.

Similarly, good sleep might lower hostile responding, even in those individuals high in trait hostility (Taylor et al, 2013). 
The finding that sleep quantity was unrelated to both aggression and hostility measures is broadly consistent with previous research showing that sleep quality relates better to multiple measures of health than sleep quantity (Pilcher et al., 1996). In particular, findings show that the subjective perception of sleep quality rather than sleep duration might be the crucial determinant of aggressive and hostile behaviour (Barker et al., 2016). Findings of the current study therefore confirm that it is perceived sleep quality rather than sleep quantity that is associated with increased aggression and hostility.

\section{Well-being and sleep quality and quantity}

Results confirmed that sleep disturbances relate to lower levels of psychological well-being. These results are consistent with earlier research reporting that positive affect and psychological well-being is inversely associated with sleep problems (Steptoe et al, 2008), and other studies reporting higher rates of anger, sadness, and fear in their sleep-deprived participants (Franzen et al., 2009; Walker, 2009). The relationship between sleep and psychological well-being is likely to be bidirectional, with sleep disturbances lowering positive affect and well-being, and positive psychological states promoting better sleep (Steptoe et al., 2008). Consequently, the current findings support recent literature on sleep deprivation indicating a previously poorly considered role for sleep in regulating emotional experiences.

\section{Limitations}

There are a number of limitations to acknowledge. First, the data is based on self-report and the accuracy of this cannot be verified. It could suffer from biased responding, such as over or under-reporting of symptoms. Even though self-report measures allow for larger samples to be collected, objective measures would nevertheless be valuable supplements in any future replication of the current study. The current study is also cross-sectional and correlational in nature. In the absence of a longitudinal component it is not possible to make cause and effect judgements. Consequently, no causal determinations regarding the link between sleep, aggression, hostility or well-being can be made. Finally, the study did not control for a number of variables that could have an impact on the results, such as mental disorders, substance abuse, or biochemical changes in women, such as menstruation or pregnancy (Krishnan \& Collop, 2006). Future research could consider these potential factors. 


\section{Conclusion}

The current study provides some empirical support for the importance of perceptions of good quality sleep and the negative impact negative perceptions can have on levels of aggression and hostility in a nonclinical population. The findings also demonstrate that disturbed sleep can have negative implications for psychological well-being. Consequently, the study highlights the importance of targeting specific sleep problems to minimise these negative effects. Future research could expand on the current study by employing both subjective and objective measures of sleep, by adopting a longitudinal design, and by deliberately manipulating individuals' subjective perception of how well they slept and exploring the effect this manipulation has on their aggression and hostility levels. 
Table 1

Descriptive characteristics of participants

\begin{tabular}{lccc}
\hline & $\begin{array}{c}\text { German } \\
\mathbf{n = 1 0 3}\end{array}$ & $\begin{array}{c}\text { British } \\
\mathbf{n = 6 0}\end{array}$ & $\begin{array}{c}\text { Dutch } \\
\mathbf{n = 3 7}\end{array}$ \\
\hline $\begin{array}{l}\text { Average age }(\boldsymbol{S D}) \\
\text { Sex }\end{array}$ & 29 yrs $(10.9)$ & 33 yrs $(12.7)$ & 24 yrs $(4.6)$ \\
$\quad$ Male & 30 & 11 & 10 \\
$\quad \begin{array}{l}\text { Female } \\
\text { Profession }\end{array} \quad$ Student & 73 & 48 & 27 \\
$\quad$ Non-student & 59 & 24 & 21 \\
Have you ever seen a mental health provider? & 36 & 15 \\
$\quad$ Yes & 37 & & \\
$\quad$ No & 66 & 30 & 21 \\
Current use of medication & & 30 & 16 \\
$\quad$ Yes & 22 & & 9 \\
$\quad$ No & 81 & 16 & 28 \\
\hline
\end{tabular}


Table 2

Reliability of sleep, aggression and well-being measures

\begin{tabular}{lc}
\hline Measure & $\boldsymbol{\alpha}$ \\
\hline Pittsburgh Sleep Quality Index (PSQI) & .75 \\
Aggression Questionnaire (AQ) & .89 \\
Physical aggression & .82 \\
Verbal aggression & .83 \\
Anger & .83 \\
Hostility & .84 \\
Impulsive-Premeditated Aggression Scale (IPAS) & .91 \\
$\quad$ Impulsive aggression & .87 \\
Premeditated aggression & .82 \\
Psychological General Well-Being Index (PGWBI) & .89 \\
\hline
\end{tabular}


Table 3

Mean (standard deviation) values across nationalities, sex and samples

\begin{tabular}{lcccccccc}
\hline Measure & $\begin{array}{c}\text { Total } \\
\mathbf{n = 2 0 1}\end{array}$ & $\begin{array}{c}\text { German } \\
\mathbf{n = 1 0 3}\end{array}$ & $\begin{array}{c}\text { British } \\
\mathbf{n = 6 0}\end{array}$ & $\begin{array}{c}\text { Dutch } \\
\mathbf{n = 3 7}\end{array}$ & $\begin{array}{c}\text { Female } \\
\mathbf{n = 1 4 9}\end{array}$ & $\begin{array}{c}\text { Male } \\
\mathbf{n = 5 1}\end{array}$ & $\begin{array}{c}\text { Student } \\
\mathbf{n = 1 0 4}\end{array}$ & $\begin{array}{c}\text { Non- } \\
\text { student } \\
\mathbf{n = 9 5}\end{array}$ \\
\hline Quality of sleep* & 1.07 & 0.95 & 1.23 & 1.16 & 1.1 & 0.98 & 1.02 & 1.13 \\
& $(0.77)$ & $(0.72)$ & $(0.81)$ & $(0.8)$ & $(0.75)$ & $(0.83)$ & $(0.74)$ & $(0.81)$ \\
\hline Sleep duration & 7.15 & 7.2 & 7.08 & 7.1 & 7.18 & 7.1 & 7.24 & 7.06 \\
(hours) & $(1.21)$ & $(0.99)$ & $(1.54)$ & $(1.17)$ & $(1.28)$ & $(0.97)$ & $(1.1)$ & $(1.34)$ \\
\hline Sleep index & 6.14 & 5.35 & 7.25 & 6.57 & 6.28 & 5.62 & 6.12 & 6.1 \\
(PSQI) score* & $(3.31)$ & $(2.56)$ & $(3.84)$ & $(3.69)$ & $(3.26)$ & $(3.3)$ & $(3.4)$ & $(3.22)$ \\
\hline Aggression score & 75.22 & 76.96 & 72.85 & 75.11 & 74.68 & 77.35 & 75.84 & 74.76 \\
& $(22.57)$ & $(22.57)$ & $(23.54)$ & $(20.77)$ & $(21.34)$ & $(25.71)$ & $(22.76)$ & $(22.64)$ \\
\hline IPAS & & & & & & & & \\
$\quad$ Impulsive & 34.55 & 34.41 & 34.95 & 34.43 & 34.53 & 34.37 & 33.95 & 35.34 \\
$\quad$ Aggression & $(8.0)$ & $(8.06)$ & $(7.83)$ & $(8.39)$ & $(8.06)$ & $(7.8)$ & $(7.92)$ & $(8.21)$ \\
$\quad \begin{array}{l}\text { Premeditated } \\
\text { Aggression }\end{array}$ & 27.66 & 27.2 & 28.4 & 27.68 & 27.66 & 27.5 & 27.28 & 28.27 \\
MJQ & $(6.2)$ & $(6.45)$ & $(5.73)$ & $(6.34)$ & $(6.49)$ & $(5.26)$ & $(6.5)$ & $(5.91)$ \\
$\quad \begin{array}{l}\text { Hostile } \\
\text { attributions }\end{array}$ & $(1.67)$ & $(1.69)$ & $(1.74)$ & $(1.48)$ & $(1.7)$ & $(1.57)$ & $(1.7)$ & $(1.57)$ \\
$\quad \begin{array}{l}\text { Prosocial } \\
\text { attributions }\end{array}$ & 6.3 & 6.25 & 6.33 & 6.32 & 6.45 & 5.83 & 6.03 & 6.63 \\
\hline Well-being score & $(1.67)$ & $(1.64)$ & $(1.77)$ & $(1.58)$ & $(1.7)$ & $(1.49)$ & $(1.61)$ & $(1.69)$ \\
\hline
\end{tabular}

* Lower scores indicating higher quality 
Table 4

Means and standard deviations (SD) across sleep quality levels

\begin{tabular}{lcccc}
\hline & $\begin{array}{c}\text { Very bad } \\
\text { sleep quality } \\
\mathbf{n = 9}\end{array}$ & $\begin{array}{c}\text { Fairly bad } \\
\text { sleep quality } \\
\mathbf{n = 4 0}\end{array}$ & $\begin{array}{c}\text { Fairly good } \\
\text { sleep quality } \\
\mathbf{n = 1 0 9}\end{array}$ & $\begin{array}{c}\text { Very good } \\
\text { sleep quality } \\
\mathbf{n}=\mathbf{4 3}\end{array}$ \\
\hline $\begin{array}{l}\text { German/British/Dutch } \\
\text { Female/Male }\end{array}$ & $3 / 2 / 4$ & $15 / 17 / 8$ & $60 / 31 / 18$ & $25 / 10 / 7$ \\
$\begin{array}{l}\text { Student/Non-student } \\
\text { Aggression Scale }\end{array}$ & $6 / 3$ & $30 / 10$ & $84 / 25$ & $29 / 13$ \\
$\quad$ Aggressive acts over & $11.67(2.35)$ & $11.6(2.68)$ & $10.97(2.49)$ & $11.47(3.34)$ \\
$\quad$ the past month & & & & \\
$\quad$ Impulsive aggression & $35.22(6.48)$ & $35.33(7.04)$ & $34.11(8.62)$ & $34.79(7.66)$ \\
$\quad$ Premeditated & $27.89(4.96)$ & $27.05(6.2)$ & $27.44(6.2)$ & $28.74(6.49)$ \\
$\quad$ aggression & & & & \\
Making Judgments & & & & \\
Questionnaire & & & & \\
$\quad$ Hostile attributions & $3.67(1.66)$ & $3.6(1.65)$ & $3.34(1.66)$ & $2.86(1.67)$ \\
$\quad \begin{array}{l}\text { Prosocial attributions } \\
\text { Well-being index }\end{array}$ & $6.0(1.87)$ & $6.2(1.59)$ & $6.29(1.67)$ & $6.47(1.72)$ \\
\hline
\end{tabular}




\section{References}

Ali, N.J., Pitson, D., \& Stradling, J.R. (1996). Sleep disordered breathing: Effects of adenotonsillectomy on behaviour and psychological functioning. International Journal of Pediatric Otorhinolaryngology, 36(1), 84-91.

Anderson, C.A., \& Bushman, B.J. (2002). Human Aggression. Annual Review Psychology, $53,27-51$.

Barker, L.F., Ireland, J.L., Chu, S., \& Ireland, C.A. (2016). Sleep and its association with aggression among prisoners: Quantity or quality? International Journal of Law and Psychiatry. Advance online publication.

Benca, R. M. (1996). Sleep in psychiatric disorders. Sleep Disorders, 14(4), 739-764.

Buboltz, W. C., Brown, F., \& Soper, B. (2001). Sleep habits and patterns of college students: A preliminary study. Journal of American College Health, 50(3), 131-135.

Buss, A. H., \& Perry, M. P. (1992). The aggression questionnaire. Journal of Personality and Social Psychology, 63, 452-459.

Buysse, D. J., Reynolds, C. F., Monk, T. H., Berman, S. R., \& Kupfer, D. J. (1989). The Pittsburgh Sleep Quality Index: a new instrument for psychiatric practice and research. Psychiatry Research, 28(2), 193-213.

De Paula, H.M., \& Hoshino, K. (2002). Correlation between the fighting rates of REM sleepdeprived rats and susceptibility to the 'wild running' of audiogenic seizures. Brain Research, 926(1-2), 80-85.

Draganich, C., \& Erdal, K. (2014). Placebo sleep affects cognitive functioning. Journal of Experimental Psychology: Learning, Memory, and Cognition, 40(3), 857-864.

Dupuy, H.J. (1984). The Psychological General Well-being (PGWB) Index. In: Wenger, N.K., Mattson, M.E., Furburg, C.D., \& Elinson, J., editor. Assessment of Quality of Life in Clinical Trials of Cardiovascular Therapies. New York: Le Jacq Publishing.

Ellis, M., Weiss, B., \& Lochman, J. (2009). Executive Functions in Children: Associations with Aggressive Behavior and Appraisal Processing. Journal of Abnormal Child Psychology, 37(7), 945-956.

Franzen, P. B., Buysse, D. J., Dahl., R. E., Thompson, W., \& Siegle, G. J. (2009). Sleep deprivation alters pupillary reactivity to emotional stimuli in healthy young adults. Biological Psychology, 80(3), 300-305.

Grossi, E., Groth, N., Mosconi, P., Cerutti, R., Pace, F., Compare, A., \& Apolone, G. (2006). Development and validation of the short version of the Psychological General Wellbeing Index (PGWB-S). Health and Quality of Life Outcomes, 4(1), 88. 
Harvey, A. G., Stinson, K., Whitaker, K. L., Moskovitz, D., \& Virk, H. (2008). The subjective meaning of sleep quality: a comparison of individuals with and without insomnia. Sleep, 31(3), 383-393.

Haynes, P.L., Bootzin, R.R., Smith, L., Cousins, J., Cameron, M., \& Stevens, S. (2006).

Sleep and aggression in substance-abusing adolescents: Results from an integrative, behavioral sleep treatment pilot program. Sleep, 29(4), 512-20.

Ireland, J.L., \& Culpin, V. (2006). The relationship between sleeping problems and aggression, anger, and impulsivity in a population of juvenile and young offenders. Journal of Adolescent Health, 38, 649-55.

Ireland, J. L., Ireland, C. A., Lewis, M., Jones, C., Keeley, S. (in press). Affective, Cognitive and Lifestyle (ACL): Initial development of an implicit and explicit approach to assess psychopathy. International Journal of Law and Psychiatry.

Kahn-Greene, E. T., Lipizzi, E. L., Conrad, A. K., Kamimori, G. H., \& Killgore, W. D. S. (2006). Sleep deprivation adversely affects interpersonal responses to frustration. Personality and Individual Differences, 41, 1433-1443.

Kamphuis, J., Meerlo, P., Koolhaas, J., \& Lancel, M. (2012). Poor sleep as a potential causal factor in aggression and violence. Sleep Medicine, 13(4), 327-334.

Koffel, E., \& Watson, D. (2009). The two-factor structure of sleep complaints and its relation to depression and anxiety. Journal of Abnormal Psychology, 118(1), 183-194.

Krishnan, V., \& Collop, N. A. (2006). Gender differences in sleep disorders. Current Opinion in Pulmonary Medicine, 12(6), 383-389.

Licklider, J. C. R., \& Bunch, M. E. (1946). Effects of enforced wakefulness upon growth and the maze learning performance of white rats. Journal of Comparative Psychology, 39, 339-350.

Mitchell, R. B., \& Kelly, J. (2006). Long-term changes in behavior after adenotonsillectomy for obstructive sleep apnea syndrome in children. Otolaryngology - Head and Neck Surgery, 134(3), 374-378.

Morgan, J. P. (2004). Psychology of Aggression. New York, NY: Nova Science Publisher.

Nasby, W., Hayden, B., \& DePaulo, B. M. (1980). Attributional bias among aggressive boys to interpret unambiguous social stimuli as displays of hostility. Journal of Abnormal Psychology, 89(3), 459.

Nebes, R. D., Buysse, D. J., Halligan, E. M., Houck, P. R., \& Monk, T. H. (2009). Selfreported sleep quality predicts poor cognitive functioning in healthy older adults. Journal of Gerontology: Psychological Sciences, 64B(2), 180-187. 
O’Brien, L.M., Lucas, N.H., Felt, B.T., Hoban, T.F., Ruzicka, D. L., Jordan, R., Guire, K., \& Chervin, R.D. (2001). Aggressive behavior, bullying, snoring, and sleepiness in schoolchildren. Sleep Medicine, 12(7), 652-658.

Pilcher, J. J., Douglas, R. G., \& Sadowsky B. (1996). Sleep quality versus sleep quantity: relationships between sleep and measures of health, well-being and sleepiness in college students. Journal of Psychosomatic Research, 42(6), 583-596.

Sleep Cycle (2014). U.S. has the lowest sleep quality score in the world. Can be retrieved from: https://www.sleepcycle.com/news/sleep-quality-world/

Stanford, M. S., Houston, R. J., Mathias, C. W., Villemarette-Pittman, N. R., Helfritz, L.E., \& Conklin, S. M. (2003). Characterizing aggressive behavior. Assessment, 10, 183-190.

Steptoe, A., O’Donnell, K., Marmot, M., \& Wardle, J. (2008). Positive affect, psychological well-being, and good sleep. Journal of Psychosomatic Research, 64(4), 409-415.

Taylor, N. D., Fireman, G. D., \& Levin, R. (2013). Trait hostility, perceived stress, and sleep quality in a sample of normal sleepers. Sleep disorders, April 2013. 1 - 8.

The Sleep Council (2013). The Great British Bedtime Report. Can be retrieved from: http://www.sleepcouncil.org.uk/wp-content/uploads/2013/02/The-Great-BritishBedtime-Report.pdf

Tsuchiyama, K., Terao, T., Wang, Y.M., Hoaki, N., \& Goto, S. (2013). Relationship between hostility and subjective sleep quality. Psychiatry Research, 209(3), 545-548.

Walker, M. P. (2009). The role of sleep in cognition and emotion. Annals of the New York Academy of Science, 1156(1), 168-197. 